\title{
Supporting LV Distribution Network Voltage Using PV Inverters Under High EV Penetration
}

\author{
Emmanuel Akakabota \\ Network Operations \\ UK Power Networks \\ Herts, UK \\ Emmanuel.Akakabota@ukpowernetwo \\ rks.co.uk
}

\author{
Gobind Pillai \\ School of Science, Engineering and \\ Design \\ Teesside University \\ Middlesbrough, UK \\ G.G.Pillai@tees.ac.uk
}

\author{
Michael Allison \\ School of Science, Engineering and \\ Design \\ Teesside University \\ Middlesbrough, UK \\ M.Allison@tees.ac.uk
}

\begin{abstract}
The growing popularity of Electric Vehicles (EV) as an alternative to fossil-fuel-driven vehicles has immense environmental appeal. Considering the effects on distribution networks, which were not designed to support such loads, several challenges are bound to be encountered in a future with purely EVs. One of such technical challenges is the effect of charging several EVs at the same time on distribution network voltage. While coordinated charging is one solution, reactive power compensation can be used to support voltage at the point of connection without the need for a centralised control. This paper explores the feasibility of using installed photovoltaic (PV) inverters as voltage compensation devices in Low Voltage (LV) distribution networks. A reactive power controller was developed in Simulink for PV inverters. The case study of a UK LV network for the winter season was used to investigate the feasibility. Results using a cumulative under-voltage index (CUVi) developed to quantify the contributions of the PV inverter reactive power compensation to network voltage support shows that for up to $30 \% \mathrm{EV}$ penetration, the available PV capacity alone can completely eliminate under-voltage incidents.
\end{abstract}

Keywords-EV, PV inverter, distribution network, reactive power compensation

\section{INTRODUCTION}

With recent government announcements expected to make EVs feature more prominently in the future [1], the impacts this would have on distribution networks needs to be placed in focus. It is not unlikely that severe under-voltage incidents will occur in LV networks with high penetration of EVs and little control over charging times. For a network with after diversity maximum demand (ADMD) of $1.3 \mathrm{kVA}$, even slow charging at $3 \mathrm{~kW}$ can have a significant impact on loading and hence voltage drop. This effect is pronounced in distribution networks during the evening peak when EV charging loads are superimposed on existing domestic loads. Researchers have proposed different algorithms for smart charging in LV networks using decentralised [2] and centralised [3] approaches. Additionally, some researchers have proposed charging at capacitive power factor [4] to reduce the occurrences of expected voltage violations, while some argue that this may need to be combined with the smart charging techniques to be effective in LV networks having low $\mathrm{X} / \mathrm{R}$ ratio [5].

The impacts of integrating PV systems to LV distribution networks has been investigated in a number of research works [6-7]. In addition to harmonic distortion, net power flow direction and power factor, voltage profile is one of the main network parameters reported as affected, particularly at high levels of PV penetration.

Over-voltage is highly probable during periods of high PV production and low demand. A study of the impacts of high
PV penetration on a LV network in an urban settlement in Sri Lanka [8] reveals that at $50 \%$ penetration voltage violations occur at the end of longest feeder; in this study, penetration is defined as the ratio of peak installed PV rating to LV transformer rating. The authors also suggest that the location of the PV inverter influences the feeder voltage rise and that poor power factor at the transformer secondary is a consequence of operating the PV inverters at unity power factor.

Two methods of mitigating voltage rise are commonly reported in literature: active power curtailment (APC) and reactive power compensation (RPC). RPC has been reported to be particularly effective for reducing overvoltage incidents in networks with a high $\mathrm{X} / \mathrm{R}$ ratio [9]. RPC at fixed power factor operation requires the injection of some active power, while volt/Var control can activate RPC without the need for active power injection. For EVs, the concept of smart charging is similar to APC strategy used for overvoltage prevention as it regulates the network voltage by changing the active power demand (generation). On the other hand, capacitive charging is akin to RPC as capacitive reactive power is added to the network as active power is drawn. Both these concepts are linked to the management of EV charging.

In this paper, the authors propose to use the PV inverter during periods of high EV charging demand to supply capacitive power to support the LV network. As, at night, no PV production is expected, the full capacity of the inverter will be available for this RPC scheme. There has been some effort towards utilising PV inverters for voltage support: the concept of PV-STATCOM is based on the control of PV inverters in solar farms, usually three-phase inverters connected to the medium (MV) distribution grid, to provide reactive power compensation (RPC) and voltage support [10]. However, in LV distribution, PV inverters are connected to single-phase and EV chargers, depending on charging rate, to a single phase or three phase. There is scanty evidence of work in this area exploring the use of PV inverters for RPC in single phase networks with high penetration of EV. The feasibility of utilising PV inverters for RPC is investigated using the case study of a UK LV distribution network.

The remainder of this paper is organised as follows: Section II details the methodology followed; results are discussed in Section III and Conclusions are drawn in Section IV.

\section{Methodology}

\section{A. Case study LV distribution network and load profile data}

The network under study consists of one $11 / 0.4 \mathrm{kV}$ transformer with four outgoing feeders as shown in Fig. 1. The key assumptions used in this study are as follows:

- the network is a balanced three-phase network 
- $\quad$ each feeder is connected to 100 homes, with the homes distributed evenly across phases

- $\quad$ every house is assumed to have a similar load profile, and as such several houses can be lumped together

- the detailed feeder is subdivided into 6 bus sections spaced equally $100 \mathrm{~m}$ apart

One feeder was modelled in detail while the other three feeders were modelled as lumped loads. For ease of calculations, the detailed feeder was assumed to have 108 houses distributed across six sections.

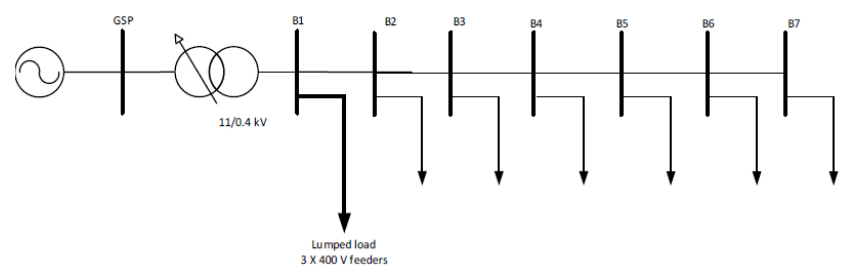

Fig. 1. One-line diagram of the case study LV distribution network.

The load profile data for was obtained from [11] based on a calculation of the ADMD referenced to 100 consumers on an outgoing $400 \mathrm{~V}$ feeder of a typical UK distribution network. The summer and winter load (ADMD) profiles with a peak of $1.3 \mathrm{kVA}$ in the winter season can be seen in Fig. 2. Winter season, owing to its higher peak ADMD was used for the feasibility investigations in this study, as under-voltage is more prominent during higher loadings.

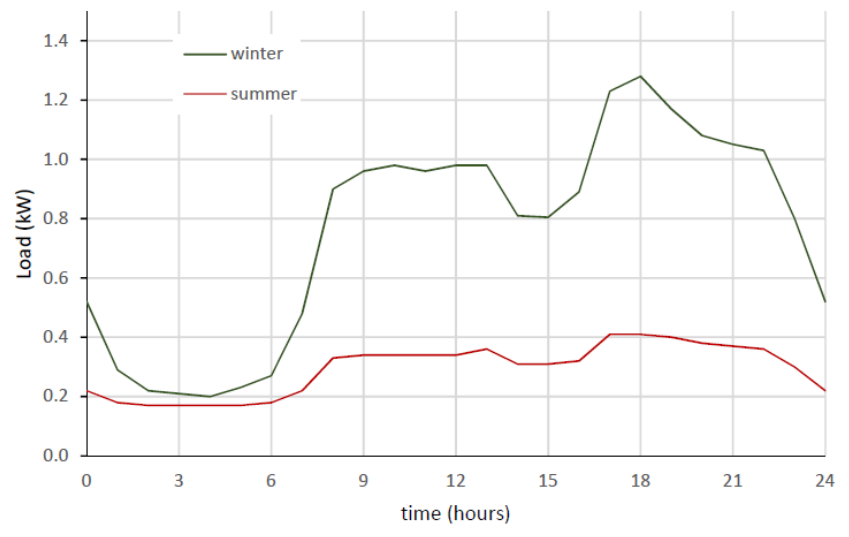

Fig. 2. Load profile data for the case study.

\section{B. EV Charging}

EV charging considered in this study is based on a $24 \mathrm{kWh}$ Nissan Leaf equipped with a $3 \mathrm{~kW}$ charger for slow charging. This is considered a realistic charging scenario for the current state of single-phase slow charging [12]. The following assumptions were made for the purpose of load flow analysis:

- all electric vehicles across the network are uniform

- charging begins at $6 \mathrm{pm}$ for all vehicle owners (uncoordinated charging)

- battery state of charge (SoC) pre-charging is 30\%

- time taken to charge is simply the product of depth of discharge (DoD) and battery capacity divided by the charger rating

For uncoordinated charging, the simplification of the charging data is expected to have little impact on the results obtained; the key factors that influence voltage rise being the charging start time and charger peak power at start of charging. For the purpose of this study, the penetration of electric vehicles is defined as the ratio of the number of electric vehicles to the number of customers on the specified feeder. A peak penetration of $50 \%$ in winter was used in this network as this is the penetration beyond which the transformer was loaded in excess of $160 \%$ for four hours in a day, the recommended limit [13]. Fig. 3 shows the loading on the $1000 \mathrm{kVA}$ transformer on a typical winter day with $50 \%$ EV penetration.

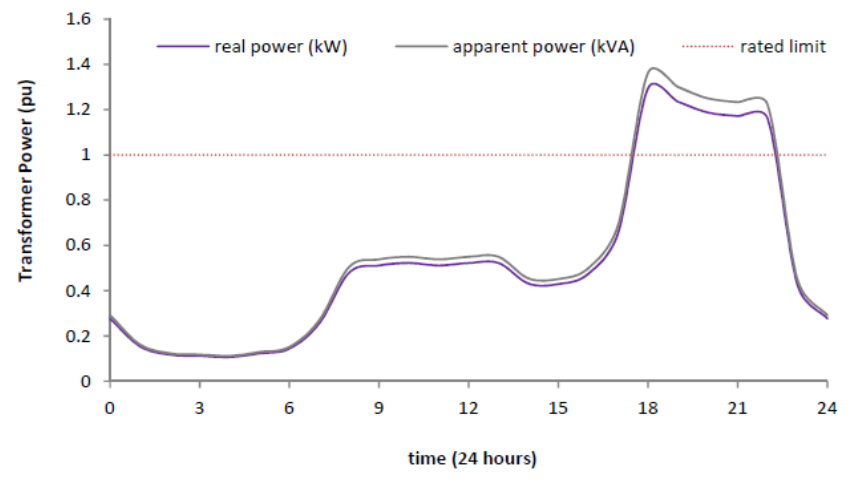

Fig. 3. Transformer loading on typical winter day with $50 \%$ EV penetration.

\section{PV power production}

Middlesbrough, UK was chosen as the location of interest and the hourly PV production data per $\mathrm{kWp}$ from a typical PV system over the course of a year was derived using PVGIS 5 (http://re.jrc.ec.europa.eu/pvg_tools/en/tools.html\#HR). The typical PV system size considered for this study was $4 \mathrm{kWp}$ which attracted the highest feed-in-tariff in the UK [14]. In this study, the penetration of PV systems was described as the number of houses on the feeder having a PV system. Different penetration levels of PV were considered and to avoid over voltage events, a maximum value of $50 \%$ was used in this study - assuming hosting capacity to be determined only by voltage violations. Fig. 4 shows the per $\mathrm{kWp}$ PV power production profiles for selected days in summer and winter.

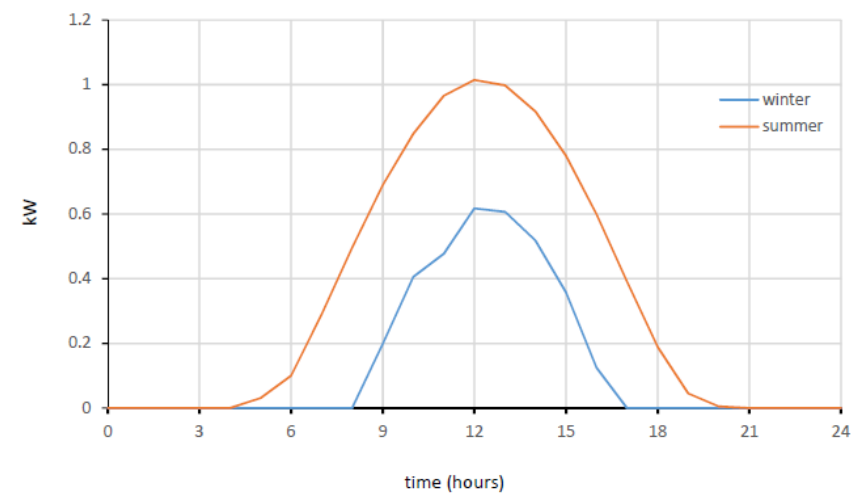

Fig. 4. Transformer loading on typical winter day with $50 \%$ EV penetration.

\section{Reactive power compensation available from $P V$ inverter}

The reactive power capability of an inverter is governed by its rated apparent power and active power production according to equation 1 [15]:

$$
\left|Q_{\text {inv }}\right|=\sqrt{\left(S_{\text {rated }}^{2}-P_{\text {inv }}^{2}\right)}
$$


As such, with no active power production at night, the full capacity of the inverter is available for RPC. Applying equation 1 and the PV power production profile of Fig.4, it is possible to determine just how much reactive power can be injected from an inverter connected to a $4 \mathrm{~kW}$ PV system having an inverter sizing ratio of 1.0. Fig. 5 shows the reactive power available over the selected days for both winter and summer.

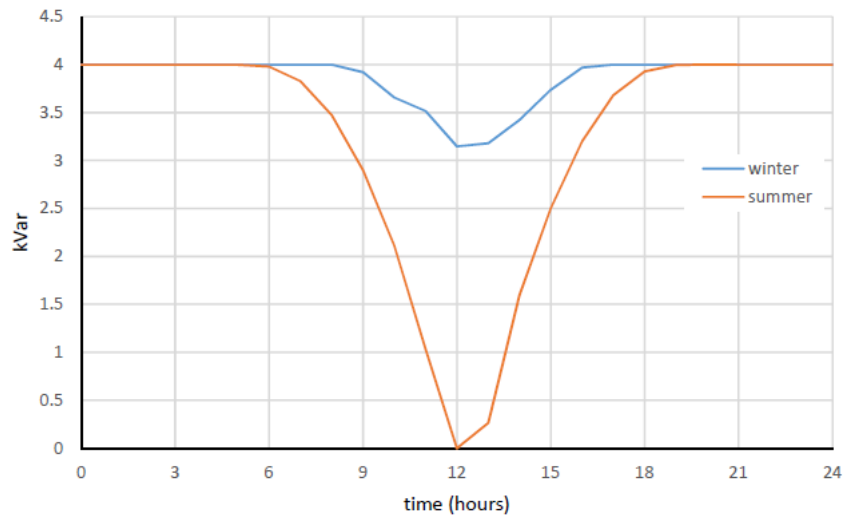

Fig. 5. Reactive power available from a typical 4 kVA PV inverter on selected winter and summer days.

\section{E. Simulink modelling of reactive power control using $P V$ inverters}

The schematic diagram of the grid-connected PV inverter is shown in Fig. 6. The feeder resistance and reactance are shown, as well as the load resistance and reactance. The passive elements in the inverter's filter primarily serve to filter out the current harmonics, but also aid the reactive power transfer to/from the inverter. The DC-link capacitor is a key element in the reactive power control strategy as it provides the voltage source at night when PV produces no power. Control of active/reactive power through the PV inverter is achieved by d-q reference frame control. The control scheme is detailed in Fig. 7. Simulink was used to build the converter and control circuitry as shown in Fig. 8. Fig. 9 shows the Simulink block for the reactive power controller.

\section{RESULTS AND DISCUSSION}

The feasibility of supporting network voltage under high $\mathrm{EV}$ penetration using the RPC scheme is investigated in this section. To do this, a portion of the network feeder under investigation (phase A) was replicated in Simulink and simulated together with the converter model developed in section III. E. As mentioned earlier the detailed LV feeder had 108 houses distributed across six sections. The network model showing only a single phase was configured in Simulink as follows:

- $\quad$ Each bus node consists of 6 houses $(18 / 3)$

- The active and reactive load at any time instant is obtained from the corresponding values from the load profile of section III.A

- $\quad$ For an EV peak charging capacity of $3 \mathrm{~kW}$, a $100 \%$ penetration is modelled as

- $\quad$ an additional $18 \mathrm{~kW}$ of active power (unity p.f. charging) at each bus node

- $\quad$ For a specified PV capacity of $4 \mathrm{~kW}$ (4 kVA at unity p.f.), a $100 \%$ penetration is modelled as $24 \mathrm{kVArs}$ of capacitive reactive power injected at each bus node from the attached PV inverter block.

The voltage profile derived from the uncompensated network was also simulated in Simulink to observe the effects of RPC. The statutory limit below which under voltage occurs is 0.94 p.u. Fig. 10 shows the effect of $30 \%$ PV RPC (injection of $7.2 \mathrm{kVArs}$ at each bus node) on a network having $30 \% \mathrm{EV}$ penetration.

From the results of Fig. 10, it was observed that with $30 \%$ PV RPC, it was possible to eliminate under voltage in a network having $20 \% \mathrm{EV}$ penetration. From a simulation of the uncompensated network, it was identified that with $20 \% \mathrm{EV}$ penetration the voltages at two buses: 6 and 7 were below the statutory limit. As can be seen from Fig. 10. Post-injection of capacitive VArs from the PV inverter the bus V7 voltage becomes 0.94 p.u. and the bus V6 voltage goes up to 0.95 p.u. The load flow is performed for $6 \mathrm{pm}$ because that is when the peak load occurs as can be seen from Fig. 3 and as such the peak voltage drop.

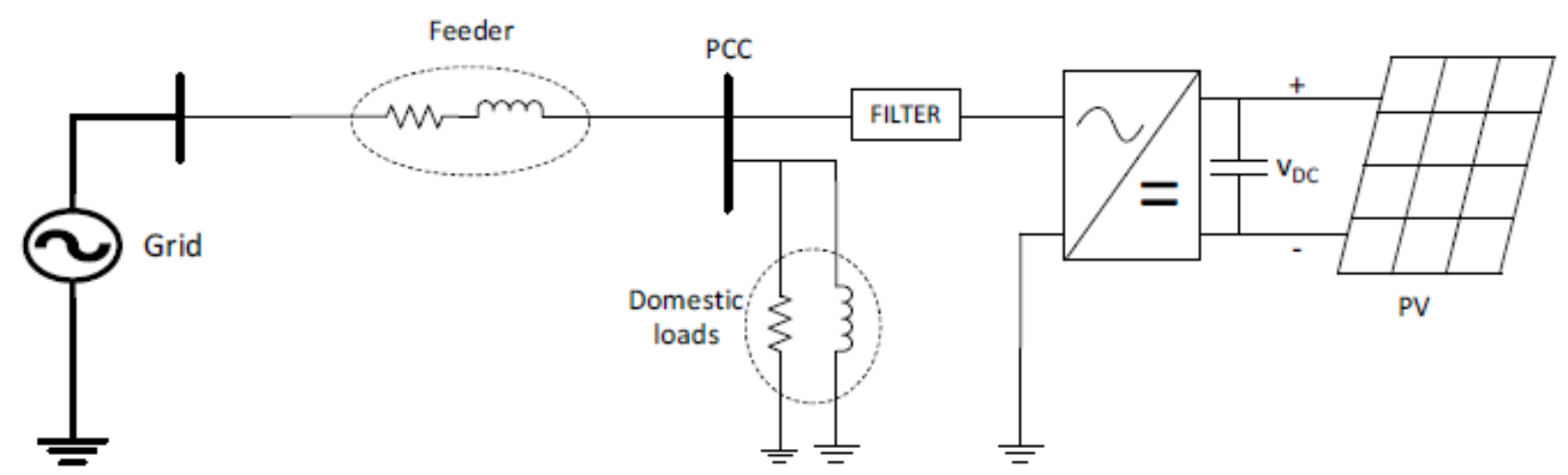

Fig. 6. Transformer loading on typical winter day with 50\% EV penetration. 


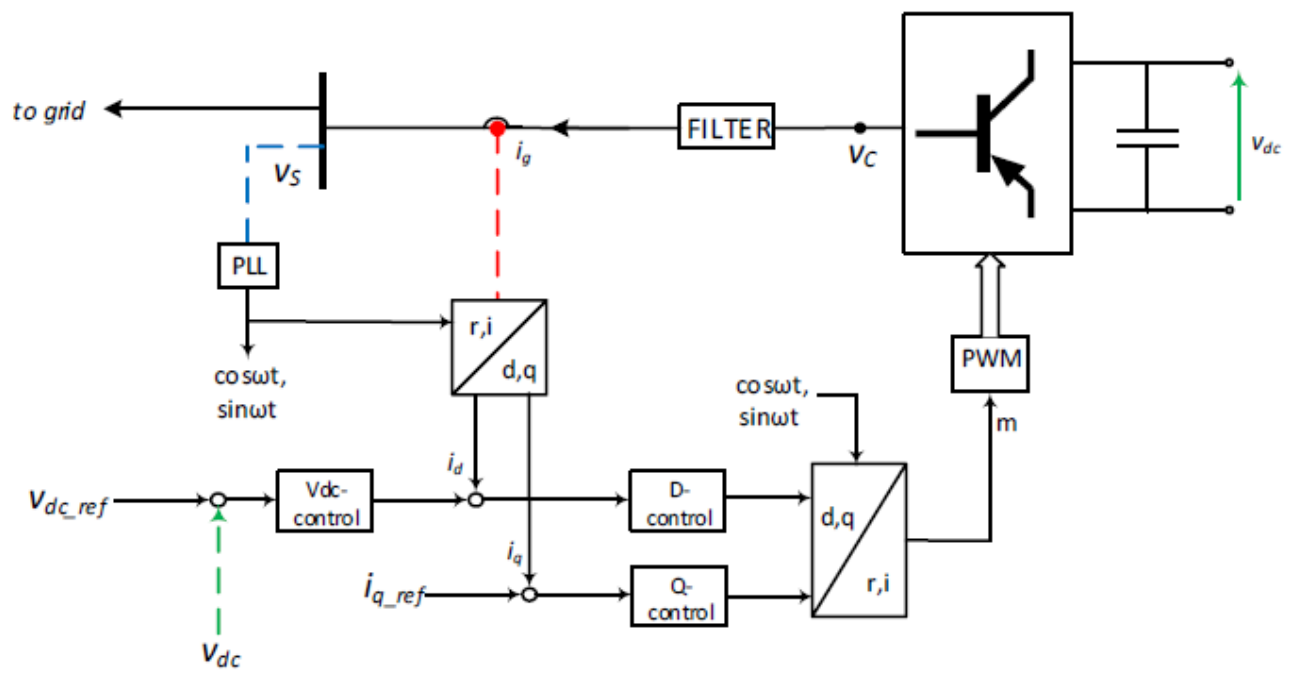

Fig. 7. PV inverter active/reactive power control schematic.

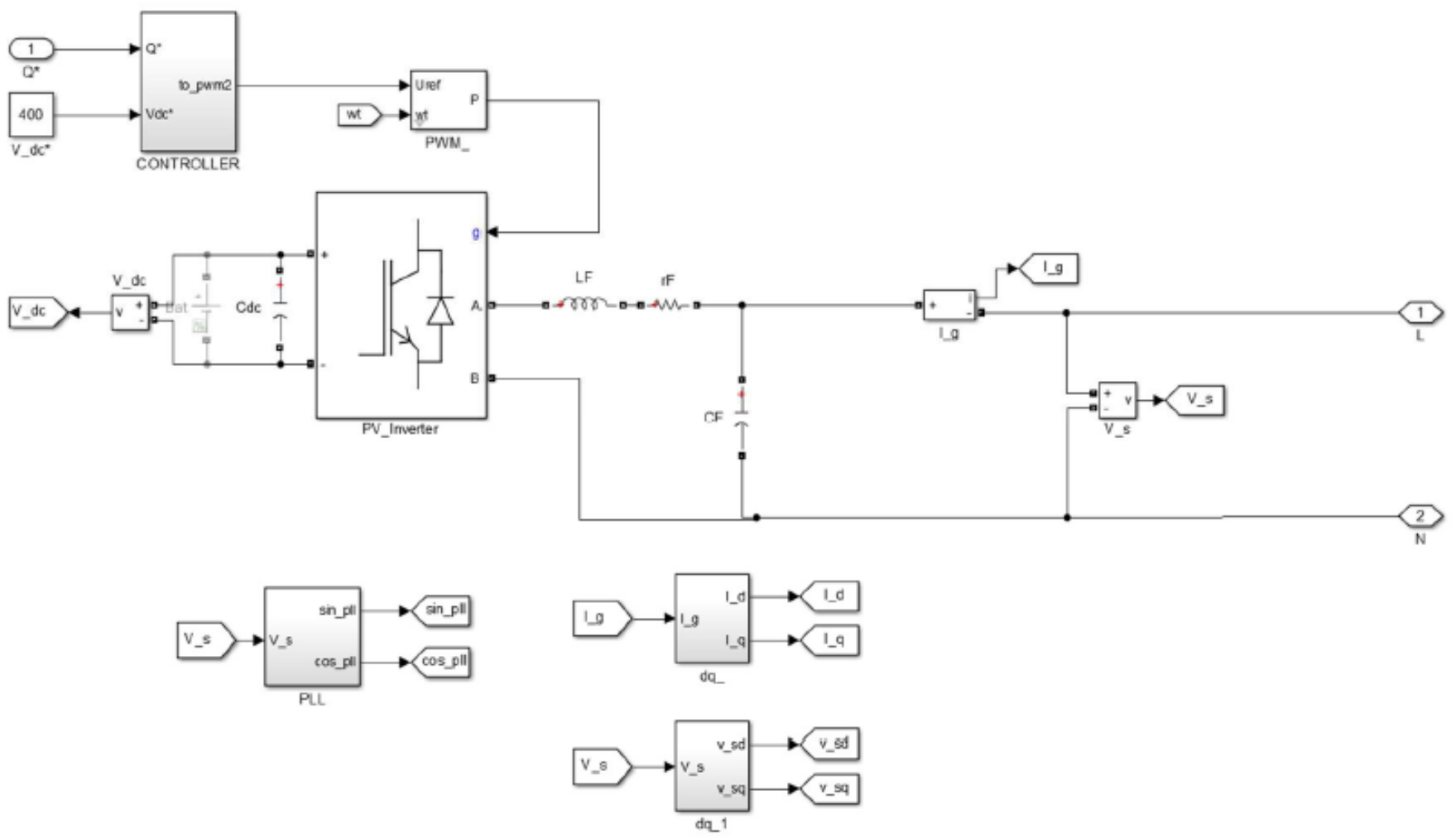

Fig. 8. Simulink block diagram for PV inverter RPC.

To evaluate the extent of voltage support that is possible in different scenarios, an index was created to quantify the actual contribution of the PV inverter RPC to network voltage support. The cumulative under voltage index (CUVi) was developed as a measure of both the severity and duration of voltage drop below the lower limit 0.94 p.u - at all the affected buses summed together. If the under voltage index for a given bus $\mathrm{x}$ is defined as:

$U V i_{x}=\sum_{i=1}^{n}\left(0.94-V_{x}\right) t_{i}$

where $V_{x}$ is the p.u. voltage of bus $\mathrm{x}$ during each time period $t_{i}$ of the total duration of the under voltage event, then the
CUVi for any given penetration scenario is simply the summation of all $U V i_{x}$ for buses experiencing under voltage during a 24-hour period. Because the voltage profile has an hourly resolution, the time periods, $t_{1}, t_{2}, . t_{n}=1$. From Fig. 3 it is clear that under voltage events would occur between 6 $\mathrm{pm}$ to $11 \mathrm{pm}$ because of EV charging; thus $n$ is usually less than or equal to 5 .

By performing load flows in Simulink - for the time periods from 18:00 to 22:00 - the effects of different PV penetration scenarios on network voltage profile for between 10 and $50 \%$ EV penetration in winter were obtained. For comparison, the CUVi without compensation (0\% penetration) is shown alongside the CUVi with different PV 
RPC levels from 10 to $50 \%$. In addition, the individual contributions of each bus is indicated by a different colour code in the clustered column chart of Fig. 11. Thus, for scenarios with a CUVi of zero, under voltage has been successfully mitigated.

The results of Fig. 11 indicate the following:

- At $40 \% \mathrm{EV}$ penetration or more, it is not possible to eliminate under voltage with the available PV RPC capacity
- At very low EV penetrations (0-20\%), 20\% PV RPC is adequate to mitigate under voltage in winter

- Excluding bus 7, the under voltage incidents are mitigated for EV penetrations of up to $40 \%$ using the available PV RPC capacity (50\% penetration)

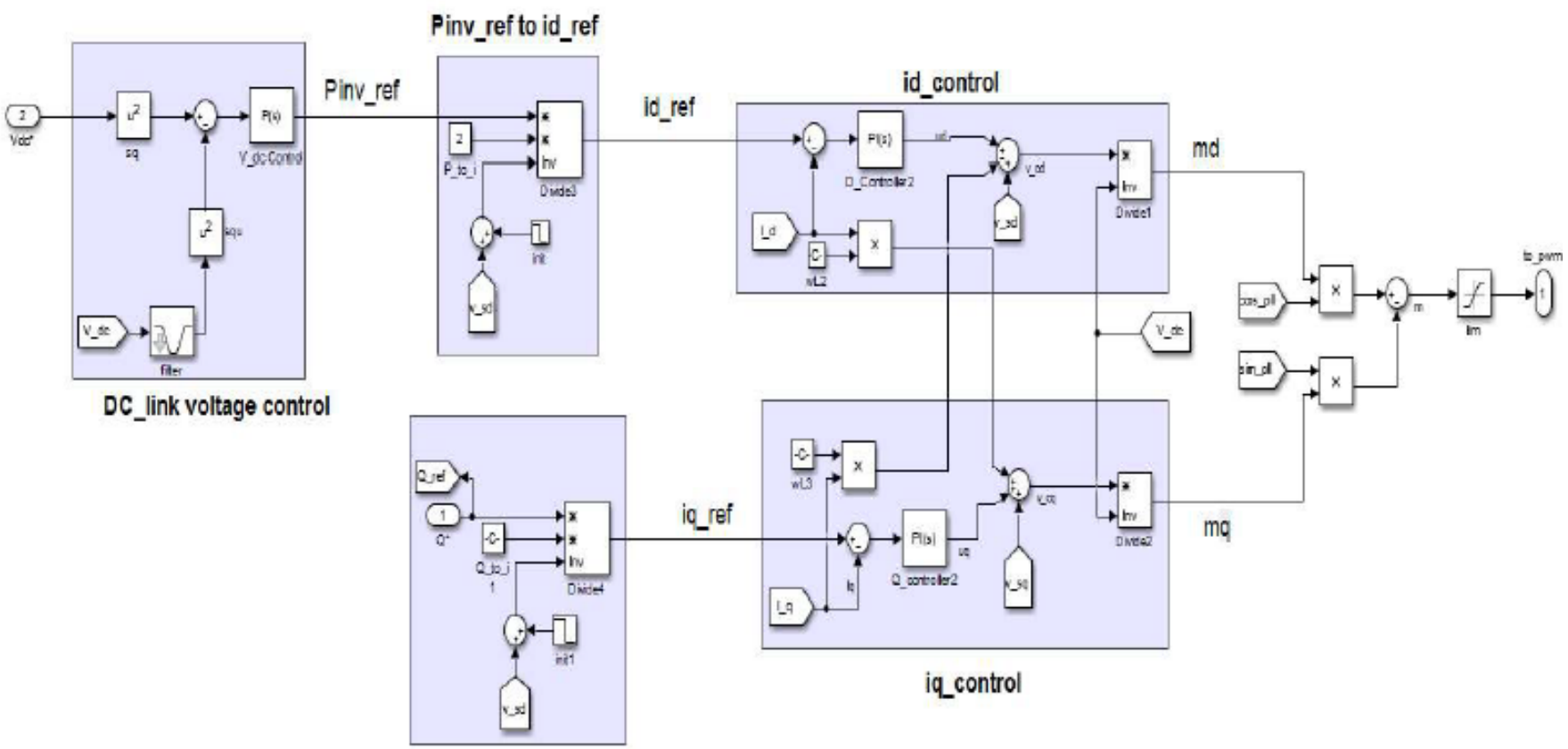

Qinv_ref to iq_ref

Fig. 9. Simulink block for reactive power controller.
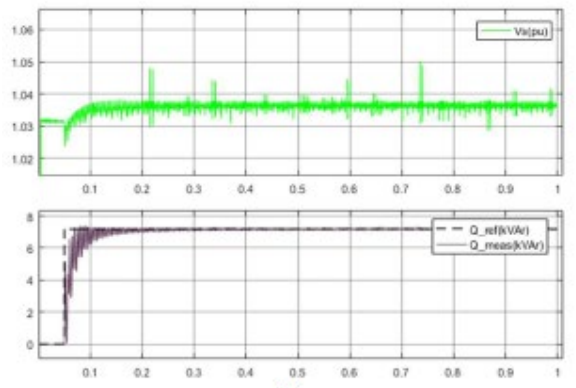

(a)
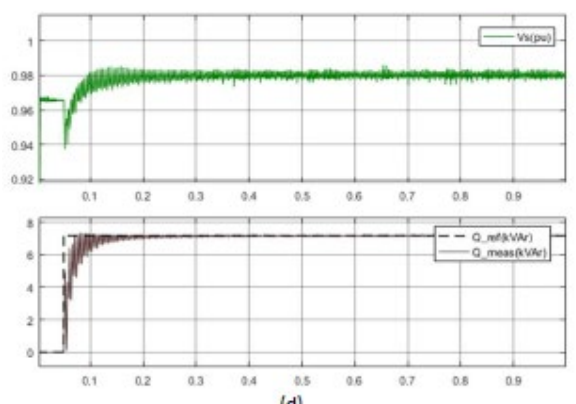

(d)
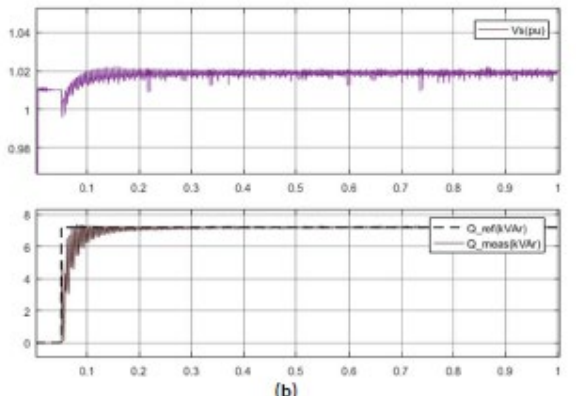

(b)
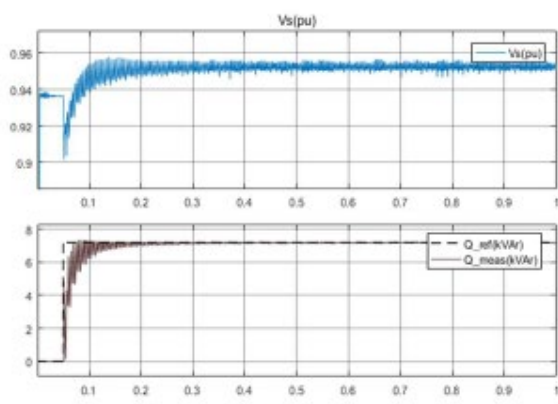
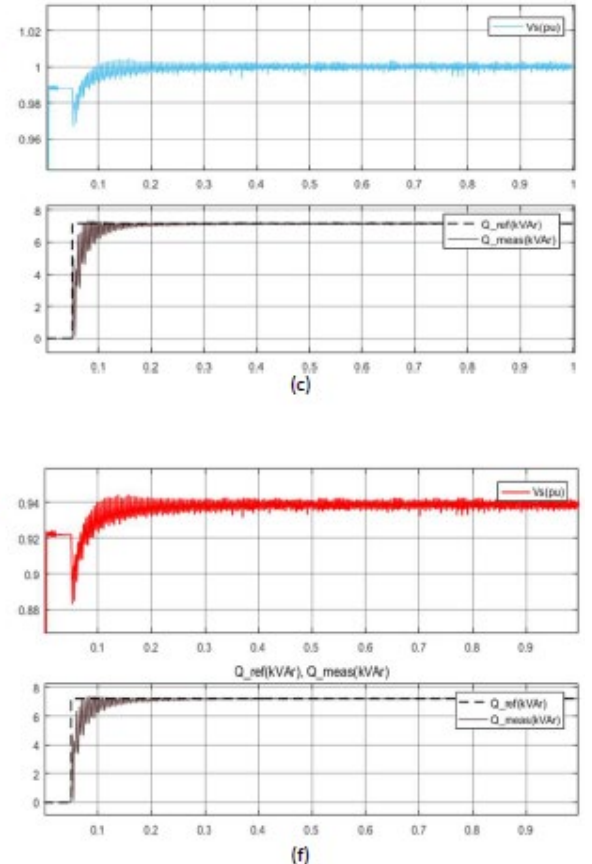

(f)

Fig. 10. Winter feeder bus voltages at $6 \mathrm{pm}$ with $20 \% \mathrm{EV}$ and $30 \% \mathrm{PV}$ RPC and corresponding reactive power injection at (a) bus 2 (b) bus 3 (c) bus 4 (d) bus 5 (e) bus 6 (f) bus 7. 


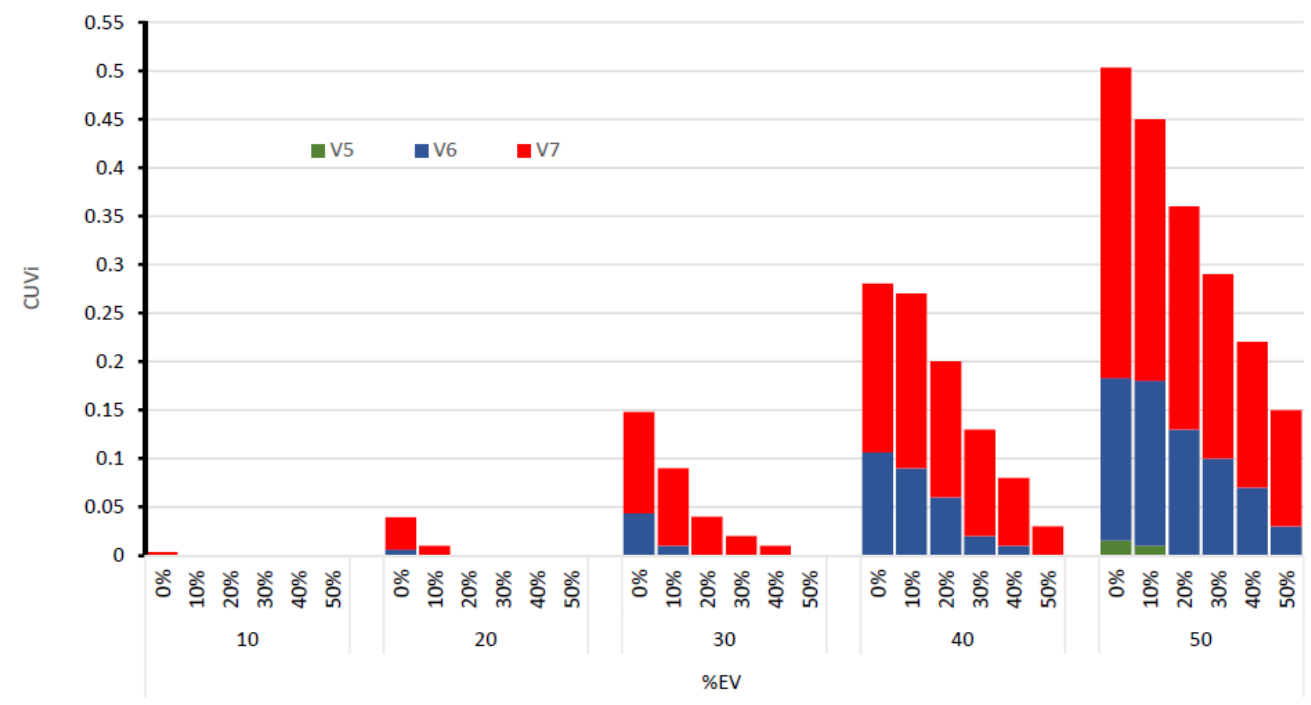

Fig. 11. Winter CUVi chart with increasing PV inverter RPC.

\section{CONCLUSIONS}

An RPC scheme has been developed for LV distribution network voltage compensation under high EV charging loads using the spare capacity of PV inverter. The reactive power controller was developed from mathematical model of dqcontrol theory and simulated in MATLAB/Simulink environment. The case study of a UK LV network for the winter season was used to investigate the feasibility of supporting LV network voltage under high EV penetration levels using the PV RPC. A CUVi index was developed to quantify the contribution of the proposed PV inverter RPC to network voltage support. For the chosen case study conditions, it was demonstrated that the PV RPC capacity alone was sufficient to eliminate under voltage events in winter for up to $30 \% \mathrm{EV}$ penetration. It is expected that network voltage support can be extended beyond the range simulated in this work to accommodate higher EV penetration levels by delaying the start of EV charging. Also, by distributing the houses in an uneven fashion across the feeder, even better penetration of both EV and PV is expected to be possible. These situations will be focussed on in future work.

\section{REFERENCES}

[1] J. Meng, Y. Mu, H. Jia, J. Wu, X. Yu and B. Qu, "Dynamic frequency response from electric vehicles considering travelling behavior in the Great Britain power system", Applied Energy, vol. 162, pp. 966-979, 2016. Available: $10.1016 /$ j.apenergy.2015.10.159.

[2] J. Cardona, J. López and M. Rider, "Decentralized electric vehicles charging coordination using only local voltage magnitude measurements", Electric Power Systems Research, vol. 161, pp. 139151, 2018. Available: 10.1016/j.epsr.2018.04.003.

[3] A. O'Connell, D. Flynn and A. Keane, "Rolling Multi-Period Optimization to Control Electric Vehicle Charging in Distribution Networks", IEEE Transactions on Power Systems, vol. 29, no. 1, pp. 340-348, 2014. Available: 10.1109/tpwrs.2013.2279276.

[4] N. Leemput, F. Geth, J. Van Roy, J. Büscher and J. Driesen, "Reactive power support in residential LV distribution grids through electric vehicle charging", Sustainable Energy, Grids and Networks, vol. 3, pp. 24-35, 2015. Available: 10.1016/j.segan.2015.05.002.
[5] A. Zecchino and M. Marinelli, "Analytical assessment of voltage support via reactive power from new electric vehicles supply equipment in radial distribution grids with voltage-dependent loads", International Journal of Electrical Power \& Energy Systems, vol. 97, pp. 17-27, 2018. Available: 10.1016/j.ijepes.2017.10.034.

[6] M. Haque and P. Wolfs, "A review of high PV penetrations in LV distribution networks: Present status, impacts and mitigation measures", Renewable and Sustainable Energy Reviews, vol. 62, pp. 1195-1208, 2016. Available: 10.1016/j.rser.2016.04.025.

[7] M. Karimi, H. Mokhlis, K. Naidu, S. Uddin and A. Bakar, "Photovoltaic penetration issues and impacts in distribution network A review", Renewable and Sustainable Energy Reviews, vol. 53, pp. 594-605, 2016. Available: 10.1016/j.rser.2015.08.042.

[8] D. Chathurangi, U. Jayatunga, M. Rathnayake, A. Wickramasinghe, A. Agalgaonkar, and S. Perera, "Potential power quality impacts on LV distribution networks with high penetration levels of solar PV", in 2018 18th International Conference on Harmonics and Quality of Power (ICHQP), 2018, pp. 1-6.

[9] F. Ding, A. Pratt, T. Bialek and F. Bell, et al, "Voltage support study of smart PV inverters on a high-photovoltaic penetration utility distribution feeder," in the IEEE 43rd Photovoltaic Specialists Conference (PVSC), Portland, OR, USA, June 2016.

[10] R. Varma, S. Rahman and T. Vanderheide, "New Control of PV Solar Farm as STATCOM (PV-STATCOM) for Increasing Grid Power Transmission Limits During Night and Day", IEEE Transactions on Power Delivery, vol. 30, no. 2, pp. 755-763, 2015. Available: 10.1109/tpwrd.2014.2375216.

[11] G. Lacey, G. Putrus, E. Bentley, D. Johnston, S. Walker, and T. Jiang, "A modelling tool to investigate the effect of electric vehicle charging on low voltage networks," in 2013 World Electr. Veh. Symp. Exhib., pp. 1-7, 2013.

[12] A.S. Rodrigo, and V.G.C. Priyanka, "Impact of High Penetration of EV Charging on Harmonics in Distribution Networks", in 2018 Moratuwa Engineering Research Conference (MERCon), pp. 340-344, 2018.

[13] IEEE Guide for Loading Mineral-Oil-Immersed Transformers and Step-Voltage Regulators, IEEE Std. C57.91-2011, Mar. 2012, New York, NY, USA

[14] G. Pillai, G. Putrus, T. Georgitsioti and N. Pearsall, "Near-term economic benefits from grid-connected residential PV (photovoltaic) systems", Energy, vol. 68, pp. 832-843, 2014. Available: 10.1016/j.energy.2014.02.085.

[15] A. R. Malekpour, A. Pahwa, and S. Das, "Inverter-based var control in low voltage distribution systems with rooftop solar PV", in 2013 North American Power Symposium (NAPS), pp. 1-5, 2013. 